\title{
Risk Factors for Postpartum Hemorrhage in a Thai-Myanmar Border Community Hospital: A Nested Case-Control Study
}

\author{
Waraporn Thepampan ${ }^{1}$, Nuchsara Eungapithum ${ }^{2}$, Krittai Tanasombatkul ${ }^{3} \mathbb{D}$ and Phichayut Phinyo ${ }^{3,4,5, * \mathbb{D}}$ \\ 1 Labor Unit, Maesai Hospital, Chiang Rai 57130, Thailand; Dang-wara@hotmail.com \\ 2 Research and Development Division, Maesai Hospital, Chiang Rai 57130, Thailand; eungyong58@gmail.com \\ 3 Department of Family Medicine, Faculty of Medicine, Chiang Mai University, Chiang Mai 50200, Thailand; \\ krittaikt@gmail.com \\ 4 Center for Clinical Epidemiology and Clinical Statistics, Faculty of Medicine, Chiang Mai University, \\ Chiang Mai 50200, Thailand \\ 5 Musculoskeletal Science and Translational Research (MSTR) Cluster, Chiang Mai University, \\ Chiang Mai 50200, Thailand \\ * Correspondence: phichayutphinyo@gmail.com; Tel.: +66-89-850-1987
}

\section{check for} updates

Citation: Thepampan, W.; Eungapithum, N.; Tanasombatkul, K.; Phinyo, P. Risk Factors for Postpartum Hemorrhage in a Thai-Myanmar Border Community Hospital: A Nested Case-Control Study. Int. J. Environ. Res. Public Health 2021, 18, 4633. https:// doi.org/10.3390/ijerph18094633

Academic Editors: Ryo Maekawa and Artur Wdowiak

Received: 26 February 2021

Accepted: 26 April 2021

Published: 27 April 2021

Publisher's Note: MDPI stays neutral with regard to jurisdictional claims in published maps and institutional affiliations.

Copyright: (c) 2021 by the authors. Licensee MDPI, Basel, Switzerland. This article is an open access article distributed under the terms and conditions of the Creative Commons Attribution (CC BY) license (https:/ / creativecommons.org/licenses/by/ $4.0 /)$.

\begin{abstract}
Postpartum hemorrhage (PPH) is a common complication of pregnancy and a global public health concern. Even though PPH risk factors were extensively studied and reported in literature, almost all studies were conducted in non-Asian countries or tertiary care centers. Our study aimed to explore relevant risk factors for PPH among pregnant women who underwent transvaginal delivery at a Thai-Myanmar border community hospital in Northern Thailand. An exploratory nested casecontrol study was conducted to explore risk factors for PPH. Women who delivered transvaginal births at Maesai hospital from 2014 to 2018 were included. Two PPH definitions were used, which were $\geq 500 \mathrm{~mL}$ and $1000 \mathrm{~mL}$ of estimated blood loss within $24 \mathrm{~h}$ after delivery. Multivariable conditional logistic regression was used to identify significant risk factors for PPH and severe $\mathrm{PPH}$. Of 4774 women with vaginal births, there were 265 (5.55\%) PPH cases. Eight factors were identified as independent predictors for PPH and severe PPH: elderly pregnancy, minority groups, nulliparous, previous $\mathrm{PPH}$ history, $\mathrm{BMI} \geq 35 \mathrm{~kg} / \mathrm{m}^{2}$, requiring manual removal of placenta, labor augmentation, and fetal weight $>4000 \mathrm{gm}$. Apart from clinical factors, particular attention should be given to pregnant women who were minority groups as PPH risk significantly increased in this population.
\end{abstract}

Keywords: risk factors; pregnancy; postpartum hemorrhage; etiology; developing countries

\section{Introduction}

Postpartum hemorrhage (PPH) is a common complication of pregnancy and a major cause of maternal mortality worldwide [1]. The ACOG reVITALize program defined PPH as a total blood loss of more than or equal to $1000 \mathrm{~mL}$, or any blood loss accompanied by clinical signs and symptoms of hypovolemic shock within $24 \mathrm{~h}$ after the birth process. However, in practice, a blood loss of more than $500 \mathrm{~mL}$ should be considered precautious, and early management should be initiated $[2,3]$. The overall prevalence of PPH in SouthEastern Asia was previously reported at 4.88\% [4]. In Thailand, the figures varied from $1.4 \%$ to $10.6 \%$, depending on the types of health care settings [5]. The highest prevalence was usually identified in district hospitals where healthcare resources were limited, and the distribution of risk factors was different from hospitals in the urban area $[5,6]$.

PPH is a life-threatening, yet preventable, condition [7]. Several studies have reported risk factors that are associated with $\mathrm{PPH}$, which were generally classified according to the labor period: antepartum factors (e.g., advanced maternal age, multiple pregnancies, history of previous PPH, taking an anticoagulant drug, and maternal anemia [8,9]), and intrapartum factors (e.g., labor induction and augmentation, prolonged third stage of labor, lacerations of birth passage, and fetal macrosomia $[10,11])$. Although some patients might 
develop PPH without any risk factor [12], determining the maternal risk factors for PPH is still important [13]. Pregnant women with multiple risks for PPH should be closely monitored and given early intervention to prevent the occurrence of PPH (e.g., active management of the third stage of labor (AMTSL) with uterotonics and controlled cord traction $[3,14])$. Apart from clinical factors, racial-ethnicity disparities and low socioeconomic status were also risk factors for PPH $[15,16]$.

Interestingly, previous studies have reported a relatively high maternal mortality among the minorities in Thailand $[17,18]$. Therefore, consideration of local or contextspecific risk factors, such as race, ethnicity, socioeconomic status, cultural belief, and accessibility to health care services, might be crucial [18]. In a recent systematic review, the Asian population was concluded as a definite risk factor for PPH [19]. However, there was only one Asian study in this systematic review, a study from Hong Kong by Lao et al. [20]. The study only focused on the association between maternal age and $\mathrm{PPH}$ and did not examine the effect of race on PPH. The other 26 studies included in the systematic review were mainly from the USA and the European countries. Therefore, the Asian population identified as risk factors was, in fact, the Asian population that was living in other non-Asian countries (e.g., USA). No studies in Thailand and other Asian countries have examined subpopulation of the Asian race as a potential risk characteristic for $\mathrm{PPH}$, and most studies were conducted in tertiary care or University-affiliated hospitals located in the urban areas $[5,11,19,21-23]$.

Therefore, there remains a gap of evidence regarding PPH risk factors for hospitals in the border area where ethnic diversity is usually found. This study aimed to assess the incidence and relevant risk factors for PPH among pregnant women who underwent transvaginal delivery at a Thai-Myanmar border hospital in Northern Thailand. Special attention was given to the effect of ethnicity and minority groups on the risk of $\mathrm{PPH}$, as no studies have provided the answer to this particular question.

\section{Materials and Methods}

\subsection{Design and Setting}

An exploratory risk factor research was conducted with a retrospective observational nested case-control design. The primary aim of the study was to identify significant determinants of PPH in the source population of pregnant women who underwent vaginal delivery at Maesai Hospital between 2014 and 2018. Maesai hospital is an upper mediumsized community hospital with 120 in-patient beds located in the Maesai district, the northernmost district of Chiang Rai province, and is a major border crossing between Thailand and Myanmar [24]. Approximately 1000 women deliver at Maesai hospital each year. In Thailand, most community hospitals do not have obstetricians in service. Therefore, complex cases (e.g., multiple pregnancies or twin and pregnant women with multiple comorbidities) are generally referred to Chiang Rai Prachanukroh hospital, the main tertiary care center of the province.

\subsection{Cases and Controls}

During the study period, we identified a cohort of 4845 women delivered at the hospital. Women who received a caesarean section or women who delivered before arrival to the hospital were excluded. In this study, we employed two definitions of PPH, which were PPH and severe PPH. PPH is defined as a blood loss of more than $500 \mathrm{~mL}$ within the first $24 \mathrm{~h}$ following delivery, while severe PPH is a blood loss of $1000 \mathrm{~mL}$ or more. The verification of postpartum blood loss was based on visual estimation of attending midwives from 2014 to 2015 and quantitative measurement with a collector bag from 2016 to 2018. All women with PPH during the period were defined as cases. For the selection of controls, we employed the tradition case-control approach [25], or exclusive sampling of controls [26]. All women without PPH were sampled as controls at the end of study. To ensure that all controls were selected from the same source population as cases, we first identified the cohort of women who delivered at our hospital during the study period. 
Hospital record numbers of all women within the cohort were collected. Cases with PPH were identified and excluded from the primary list. The remaining records in the list were used as the base for sampling of controls. For each case, two controls, or women without $\mathrm{PPH}$, delivered within the same year as the PPH case were randomly sampled from the lists of non-cases. Figure 1 presents the patient flow diagram and the matching of cases and controls.

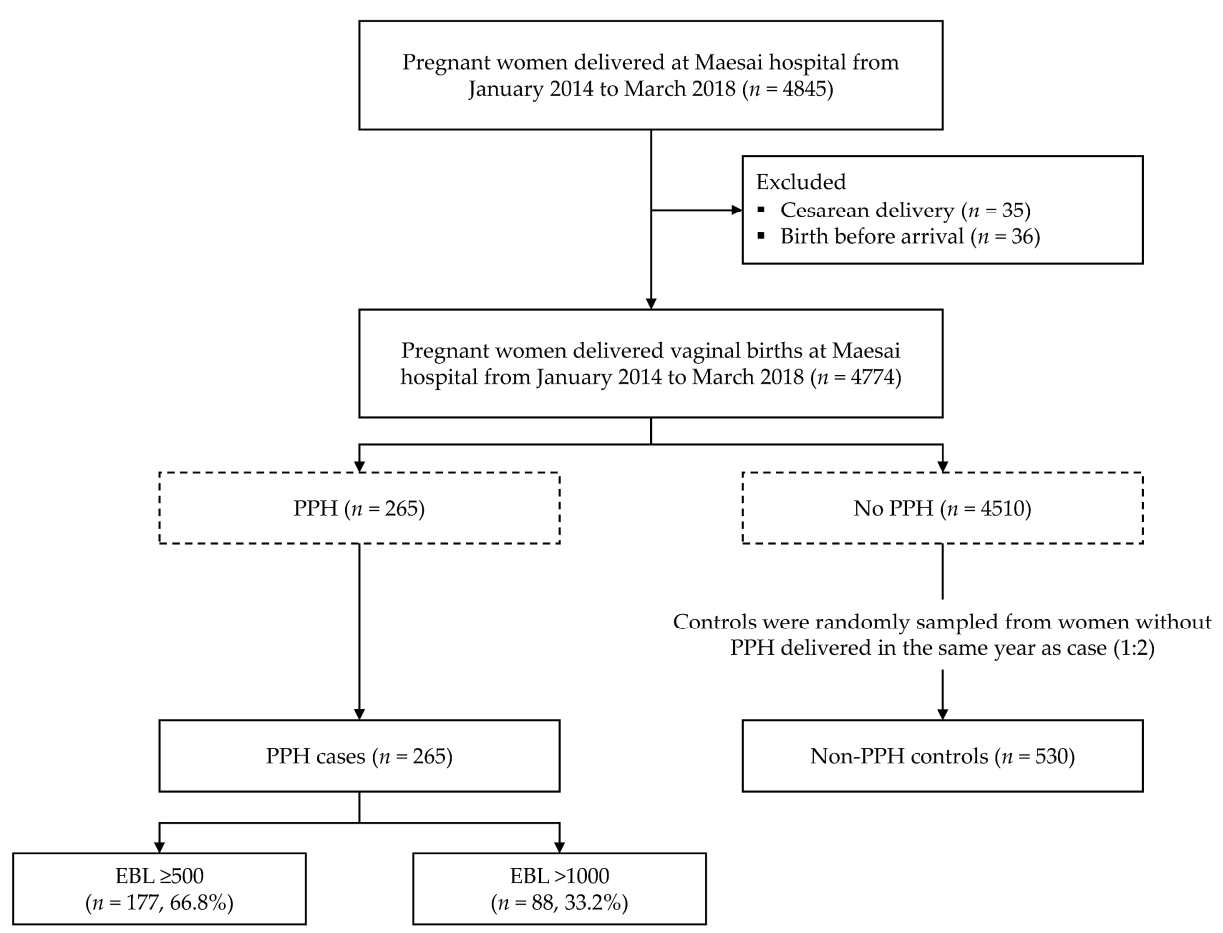

Figure 1. Patient flow diagram and the matching of cases and controls. Abbreviations: EBL, estimated blood loss; PPH, postpartum hemorrhage.

\subsection{Data Collection}

For each included patient, we reviewed routinely-documented medical and obstetric patient record forms. The data on demographic and potential risk factors were collected. These standardized forms were used for gathering clinical information from all patients upon their admissions by attending midwives. The forms record essential demographic data and potential risk characteristics for obstetrics complications encompassing all our study determinants. All the included risk factors in this study were based on a review of the evidence, clinical experience, and data available on standard record forms. Antepartum factors included maternal age, nationality, obstetrics factors (i.e., parity, antenatal care history, gestational age, maternal anemia, maternal HIV, history of previous PPH, history of previous delivery with fetal weight $>3500 \mathrm{gm}$, history of instrumental delivery, and pregnancy-induced hypertension), physical examination (i.e., BMI, fundal height, and cervical dilatation on admission). Intrapartum factors included length of each stage of labor, requirement of manual removal of placenta, type of delivery (i.e., spontaneous delivery, instrumental delivery, and Breech assisted/extraction), tear degree of the episiotomy wound, fetal weight, and estimated blood loss.

\subsection{Definitions of Terms}

Nulliparous women were women who had never gave birth (parity of zero delivery). Primiparous women were women who had gave birth once (parity of one delivery). Multiparous women were women who had gave birth more than once (parity $\geq 2$ deliveries) [27]. In our study, we categorized women in terms of parity into nulliparous and non-nulliparous women, which include both primiparous and multiparous women. Mater- 
nal anemia was defined as the hemoglobin $(\mathrm{Hb})$ level of less than $11 \mathrm{~g} / \mathrm{dL}$ according to the World Health Organization (WHO) [28]. Prolonged second stage was defined as more than $2 \mathrm{~h}$ in nulliparous and more than $1 \mathrm{~h}$ in non-nulliparous women without epidural analgesia [29]. Prolonged third stage of labor was defined as a total length of the third stage of labor that lasts more than $30 \mathrm{~min}$ [30]. Requirement of manual removal of placenta might occur earlier than $30 \mathrm{~min}$ if there were active bleeding.

\subsection{Statistical Analysis}

All statistical analyses were performed using Stata 16 (StataCorp, College Station, TX, USA). We described categorical variables with frequency and percentage and continuous variables with mean and standard deviation, or median and interquartile range, as appropriate. Fisher's exact probability test was used for identifying the significant difference of categorical variables between cases and controls. An independent t-test or Mann-Whitney $\mathrm{U}$ test was used for comparing continuous variables between cases and controls. A $p$-value of less than 0.05 was considered statistically significant.

The calculation of the overall PPH incidence was based on the number of PPH cases divided by the total number of women delivered at Maesai hospital during the entire study period. The 95\% confidence interval (CI) of the overall PPH incidence was estimated with the Clopper-Pearson method.

Multivariable conditional logistic regression was used for exploratory modeling. The dependent variable was the occurrence of PPH. The independent variables were risk factors with a statistically significant difference from the univariable analysis. In our study, the verification of endpoint was different in the two periods, visual estimation from 2014 to 2015 and quantitative measurement with collector bag from 2016 to 2018, which could potentially affect the association between study determinants and the study endpoints. For this reason, we employed the concept of stratified analysis of binary logistic regression with the use of conditional logistic modeling [31]. In this study, our patients were stratified into two study periods based on the method used for measuring estimated blood loss. The study period was used as a conditional factor in a conditional logistic model. With this approach, all patients within the primary dataset were separated into two datasets by study periods and binary logistic regression were used for separate modeling. The estimates from the stratified logistic models were then combined and presented. For each PPH definition, two conditional logistic regression models were executed separately for antepartum characteristics and intrapartum characteristics. Odds ratios (OR) with their corresponding $95 \%$ CIs were presented. As the aim was to explore for independent risk factors not to explain the causality of each factor on the endpoints, all factors within the multivariable were presented regardless of their statistical significance. No model reduction or stepwise procedure was performed. To confirm the robustness of our results, we performed a sensitivity analysis using multivariable multi-level logistic regression by using the time variable as a 2 nd level variable.

\section{Results}

We identified 265 women with PPH cases and 530 women with non-PPH controls during the study period. The overall incidence of PPH and severe PPH was 5.55\% (95\% CI $4.92 \%$ to $6.24 \%$ ) and $1.84 \%$ (95\%CI $1.48 \%$ to $2.27 \%$ ), respectively. Supplementary Table S1 presents the PPH incidence of the patient cohort in each year. The estimated blood loss was significantly different between PPH cases and non-PPH controls (968.4 \pm 431.2 (range 500-3410) vs. $257.3 \pm 120.7$ (range 30-495), $p$-value $<0.001$ ). We stratified the study samples into two study periods based on the method of outcome verification. The average overall estimated blood loss between the two study periods was not significantly different (EBL $499.45 \pm 452.76$ vs. $485.57 \pm 385.75$, $p$-value $=0.660$ ). The estimated blood loss in the PPH group was also not significantly differed between the two study periods (EBL $989.55 \pm 473.40$ vs. $932.30 \pm 347.16, p$-value $=0.298$ ). 
Although the mean age was not significantly different $(26.3 \pm 6.3$ vs. $26.1 \pm 5.8$, $p$-value $=0.644)$, there was a higher proportion of teenage pregnancy $(10.6 \%$ vs. $8.3 \%$, $p$-value $=0.040)$ and elderly pregnancy $(12.1 \%$ vs. $7.4 \%, p$-value $=0.040)$ in women with PPH than that in women without PPH. Several antepartum factors were found to be significantly different between cases and controls in the univariable analysis, which were nationality, nulliparity, antenatal care history, history of previous PPH, history of delivering of fetal weight $>3500 \mathrm{gm}$, history of instrumental delivery, body mass index at delivery, and fundal height (Table 1). The intrapartum factors are presented in Table 2. By using univariable analysis, most factors were found to be significantly different between cases and controls. These intrapartum factors included labor augmentation, type of delivery, tear degree of the episiotomy wound, fetal weight, and estimated blood loss. Only the length of 1st stage, 2nd stage of labor, and prolongation of 2nd stage of labor were not significantly different (Table 2). There were only three cases with Breech assisted/extraction, one within PPH cases and two within non-PPH controls. Thus, we did not perform statistical comparison for this variable. Supplementary Tables S2 and S3 contrast clinical characteristics, antepartum, and postpartum factors between PPH cases and non-PPH controls based on $\mathrm{EBL} \geq 1000 \mathrm{~mL}$ definition.

Table 1. Comparison of antepartum characteristics between cases and controls $(n=795)$.

\begin{tabular}{|c|c|c|c|c|c|}
\hline & \multicolumn{2}{|c|}{$\begin{array}{l}\text { PPH Cases } \\
(n=265)\end{array}$} & \multicolumn{2}{|c|}{$\begin{array}{l}\text { No PPH Controls } \\
\quad(n=530)\end{array}$} & \multirow{2}{*}{$p$-Value } \\
\hline & $\mathbf{n}$ & $(\%)$ & $\mathbf{n}$ & $(\%)$ & \\
\hline \multicolumn{6}{|l|}{ Demographic factors } \\
\hline Maternal age, (years, mean \pm SD) & 26.3 & \pm 6.3 & 26.1 & \pm 5.8 & 0.644 \\
\hline Normal age pregnancy (20-34) & 205 & $(77.4)$ & 447 & $(84.3)$ & 0.040 \\
\hline Teenage pregnancy $(<20)$ & 28 & $(10.6)$ & 44 & $(8.3)$ & \\
\hline Elderly pregnancy $(\geq 35)$ & 32 & $(12.1)$ & 39 & $(7.4)$ & \\
\hline \multicolumn{6}{|l|}{ Nationality } \\
\hline Thai & 45 & $(17.0)$ & 138 & $(26.0)$ & $<0.001$ \\
\hline Burmese & 115 & $(43.4)$ & 295 & $(55.7)$ & \\
\hline Minority/tribes & 105 & $(39.6)$ & 97 & $(18.3)$ & \\
\hline \multicolumn{6}{|l|}{ Obstetrics factors } \\
\hline \multicolumn{6}{|l|}{ Parity } \\
\hline $\begin{array}{l}\text { Non-nulliparous (primiparous and } \\
\text { multiparous) }\end{array}$ & 135 & $(50.9)$ & 363 & $(68.5)$ & $<0.001$ \\
\hline Nulliparous & 130 & $(49.1)$ & 167 & $(31.5)$ & \\
\hline \multicolumn{6}{|l|}{ Antenatal care history } \\
\hline Have ANC history & 256 & $(96.6)$ & 512 & $(96.6)$ & 1.000 \\
\hline No ANC history & 9 & $(3.4)$ & 18 & $(3.4)$ & \\
\hline \multicolumn{6}{|l|}{ Adequacy of ANC } \\
\hline Adequate ( $\geq 5$ visits) & 191 & $(72.1)$ & 433 & $(81.7)$ & 0.002 \\
\hline Inadequate ( $<5$ visits) & 74 & $(27.9)$ & 97 & $(18.3)$ & \\
\hline \multicolumn{6}{|l|}{ Gestational age } \\
\hline Preterm $(<37)$ & 14 & $(5.3)$ & 42 & $(7.9)$ & 0.311 \\
\hline Term (37-41) & 251 & (94.7) & 486 & (91.9) & \\
\hline Post term $(>41)$ & 0 & $(0)$ & 1 & $(0.2)$ & \\
\hline \multicolumn{6}{|l|}{$\begin{array}{l}\text { Presence of the following maternal } \\
\text { risk factors }\end{array}$} \\
\hline Maternal anemia & 45 & $(17.0)$ & 80 & $(15.1)$ & 0.535 \\
\hline Maternal HIV & 0 & $(0)$ & 6 & $(1.1)$ & 0.186 \\
\hline History of previous PPH & 11 & $(4.2)$ & 1 & $(0.2)$ & $<0.001$ \\
\hline $\begin{array}{l}\text { History of deliver fetal weight }>3500 \\
\text { gm }\end{array}$ & 25 & $(9.4)$ & 25 & $(4.7)$ & 0.013 \\
\hline History of instrumental delivery & 16 & $(6.0)$ & 9 & $(1.7)$ & 0.002 \\
\hline Pregnancy-induced hypertension & 7 & (2.6) & 7 & (1.3) & 0.251 \\
\hline
\end{tabular}


Table 1. Cont.

\begin{tabular}{|c|c|c|c|c|c|}
\hline & \multicolumn{2}{|c|}{$\begin{array}{c}\text { PPH Cases } \\
(n=265)\end{array}$} & \multicolumn{2}{|c|}{$\begin{array}{l}\text { No PPH Controls } \\
\quad(n=530)\end{array}$} & \multirow{2}{*}{$p$-Value } \\
\hline & $\mathbf{n}$ & $(\%)$ & $\mathbf{n}$ & $(\%)$ & \\
\hline \multicolumn{6}{|l|}{ Physical examination } \\
\hline \multicolumn{6}{|l|}{ BMI at delivery, $\left(\mathrm{kg} / \mathrm{m}^{2}\right.$, mean $\left.\pm \mathrm{SD}\right)$} \\
\hline$<25.0$ & 70 & $(26.4)$ & 157 & $(29.6)$ & $<0.001$ \\
\hline $25.0-29.9$ & 108 & $(40.8)$ & 267 & $(50.4)$ & \\
\hline $30.0-34.9$ & 59 & $(22.3)$ & 86 & $(16.2)$ & \\
\hline$\geq 35.0$ & 28 & $(10.6)$ & 20 & $(3.8)$ & \\
\hline Fundal height, $(\mathrm{cm}$, mean $\pm \mathrm{SD})$ & 35.2 & \pm 2.6 & 34.5 & \pm 2.3 & $<0.001$ \\
\hline$<36.0$ & 168 & $(63.4)$ & 447 & $(84.3)$ & $<0.001$ \\
\hline$\geq 36.0$ & 97 & $(36.6)$ & 83 & $(15.7)$ & \\
\hline \multicolumn{6}{|l|}{ Cervical dilation on admission, $(\mathrm{cm})$} \\
\hline$\leq 3 \mathrm{~cm}$ & 173 & $(65.3)$ & 340 & $(64.2)$ & 0.056 \\
\hline $4-7 \mathrm{~cm}$ & 78 & $(29.4)$ & 137 & $(25.9)$ & \\
\hline$\geq 8 \mathrm{~cm}$ & 14 & $(5.3)$ & 53 & $(10.0)$ & \\
\hline
\end{tabular}

Abbreviations: ANC, antenatal care; BMI, body mass index; HIV, Human immunodeficiency syndrome; PPH, postpartum hemorrhage; $\mathrm{SD}$, standard deviation.

Table 2. Comparison of intrapartum characteristics between cases and controls $(n=795)$.

\begin{tabular}{|c|c|c|c|c|c|}
\hline & \multicolumn{2}{|c|}{$\begin{array}{l}\text { PPH Cases } \\
(n=265)\end{array}$} & \multicolumn{2}{|c|}{$\begin{array}{l}\text { No PPH Controls } \\
\quad(n=530)\end{array}$} & \multirow[t]{2}{*}{$p$-Value } \\
\hline & $\mathbf{n}$ & $(\%)$ & $\mathbf{n}$ & $(\%)$ & \\
\hline \multicolumn{6}{|l|}{ Intrapartum factors } \\
\hline Labor augmentation & 72 & $(27.2)$ & 64 & $(12.1)$ & $<0.001$ \\
\hline $\begin{array}{l}\text { Length of 1st stage (hour, median } \\
\text { (IQR)) }\end{array}$ & 8 & $(4.5,13)$ & 7 & $(4,11.4)$ & 0.085 \\
\hline $\begin{array}{l}\text { Length of 2nd stage in nulliparous } \\
\text { (min, median (IQR)) }\end{array}$ & 10 & $(5.5,20)$ & 12 & $(4,21)$ & 0.878 \\
\hline $\begin{array}{l}\text { Length of 2nd stage in } \\
\text { non-nulliparous (min, median (IQR)) }\end{array}$ & 13 & $(6,25)$ & 10 & $(5,20)$ & 0.190 \\
\hline Prolonged 2nd stage & 9 & $(3.4)$ & 23 & $(4.3)$ & 0.572 \\
\hline $\begin{array}{l}\text { Length of 3rd stage (min, median } \\
\qquad(\mathrm{IQR}))\end{array}$ & 7 & $(5,18)$ & 6 & $(4,9)$ & $<0.001$ \\
\hline Prolonged 3rd stage & 28 & $(10.6)$ & 11 & $(2.1)$ & $<0.001$ \\
\hline $\begin{array}{c}\text { Require manual removal of placenta } \\
\text { Delivery }\end{array}$ & 35 & $(13.2)$ & 2 & $(0.4)$ & $<0.001$ \\
\hline Spontaneous delivery & 228 & $(86.0)$ & 500 & $(94.3)$ & $<0.001$ \\
\hline \multicolumn{6}{|l|}{ Episiotomy wound } \\
\hline No tear & 200 & $(75.5)$ & 420 & $(79.3)$ & $<0.001$ \\
\hline First or second degree tear & 52 & $(19.6)$ & 109 & $(20.6)$ & \\
\hline Third or fourth degree tear & 13 & $(4.9)$ & 1 & $(0.2)$ & \\
\hline \multicolumn{6}{|l|}{ Fetal weight $(\mathrm{gm}$, mean $\pm \mathrm{SD})$} \\
\hline$<3500$ & 195 & $(73.6)$ & 453 & $(85.5)$ & $<0.001$ \\
\hline $3500-4000$ & 62 & $(23.4)$ & 73 & $(13.8)$ & \\
\hline$>4000$ & 8 & $(3.0)$ & 4 & $(0.8)$ & \\
\hline
\end{tabular}

Abbreviations: IQR, interquartile range; $\mathrm{PPH}$, postpartum hemorrhage; SD, standard deviation.

Five antepartum factors, including elderly pregnancy, minority groups, nulliparous, history of previous $\mathrm{PPH}$, and $\mathrm{BMI} \geq 35 \mathrm{~kg} / \mathrm{m}^{2}$, were identified as independent predictors for PPH and severe PPH in multivariable analysis (Table 3). Inadequate ANC, and fundal height $\geq 36 \mathrm{~cm}$ were predictors for only $\mathrm{PPH}$, while Burmese nationality was a predictor for only severe $\mathrm{PPH}$ (Table 3). Although prolonged third stage of labor and requiring manual removal of placenta were both identified as statistical significance factors in the univariable analysis, only requiring manual removal of placenta was included in the multivariable model owing to clinical collinearity. Three intrapartum factors were identified 
as independent predictors for $\mathrm{PPH}$ and severe $\mathrm{PPH}$, which were requiring manual removal of placenta, labor augmentation, and fetal weight $>4000 \mathrm{gm}$ (Table 4). Instrumental delivery, Third- or Fourth-degree tear of an episiotomy wound, and fetal weight between 3500 to 4000 gm were predictors for only PPH (Table 4). The sensitivity analysis results showed no significant differences in the association between predictors and PPH occurrence when considered the correlation of women delivered within the same year (Supplementary Tables S4 and S5).

Table 3. Multivariable analysis of association between antepartum characteristics and postpartum hemorrhage $(\mathrm{n}=795)$.

\begin{tabular}{|c|c|c|c|c|}
\hline & \multicolumn{4}{|c|}{ Multivariable Analysis } \\
\hline & \multicolumn{2}{|c|}{$\mathrm{EBL} \geq 500 \mathrm{~mL}$} & \multicolumn{2}{|c|}{$\mathrm{EBL}>1000 \mathrm{~mL}$} \\
\hline & Adjusted OR $(95 \% \mathrm{CI})$ & $p$-Value & Adjusted OR $(95 \% \mathrm{CI})$ & $p$-Value \\
\hline \multicolumn{5}{|l|}{ Maternal age } \\
\hline Normal age pregnancy (20-34) & Reference & & Reference & \\
\hline Teenage pregnancy $(<20)$ & $0.94(0.52,1.70)$ & 0.845 & $1.06(0.46,2.42)$ & 0.893 \\
\hline Elderly pregnancy $(\geq 35)$ & $2.36(1.32,4.23)$ & 0.004 & $2.82(1.37,5.81)$ & 0.005 \\
\hline \multicolumn{5}{|l|}{ Nationality } \\
\hline Thai & Reference & & Reference & \\
\hline Burmese & $1.39(0.88,2.19)$ & 0.156 & $2.31(1.09,4.89)$ & 0.029 \\
\hline Minority/tribes & $3.29(2.02,5.36)$ & $<0.001$ & $3.83(1.79,8.14)$ & $<0.001$ \\
\hline \multicolumn{5}{|l|}{ Parity } \\
\hline $\begin{array}{c}\text { Non-nulliparous (primiparous and } \\
\text { multiparous) }\end{array}$ & Reference & & Reference & \\
\hline Nulliparous & $3.17(2.19,4.59)$ & $<0.001$ & $2.37(1.40,4.00)$ & 0.001 \\
\hline \multicolumn{5}{|l|}{ Adequacy of ANC } \\
\hline Adequate ( $\geq 5$ visits) & Reference & & Reference & \\
\hline Inadequate (<5 visits) & $1.66(1.11,2.48)$ & 0.013 & $1.12(0.65,1.92)$ & 0.693 \\
\hline \multicolumn{5}{|l|}{ History of previous $\mathrm{PPH}$} \\
\hline Absence & Reference & & Reference & \\
\hline Presence & $22.77(2.82,184.13)$ & 0.003 & $11.32(3.22,39.77)$ & $<0.001$ \\
\hline \multicolumn{5}{|l|}{ History of deliver fetal weight $>3500 \mathrm{gm}$} \\
\hline Absence & Reference & & Reference & \\
\hline Presence & $1.44(0.71,2.89)$ & 0.309 & $1.01(0.40,2.53)$ & 0.976 \\
\hline \multicolumn{5}{|l|}{ History of instrumental delivery } \\
\hline Absence & Reference & & Reference & \\
\hline Presence & $2.39(0.96,5.98)$ & 0.062 & $2.98(1.14,7.81)$ & 0.026 \\
\hline \multicolumn{5}{|l|}{ BMI at delivery } \\
\hline$<25.0$ & Reference & & Reference & \\
\hline $25.0-29.9$ & $0.83(0.55,1.24)$ & 0.361 & $0.93(0.51,1.69)$ & 0.820 \\
\hline $30.0-34.9$ & $1.44(0.89,2.36)$ & 0.141 & $1.62(0.81,3.16)$ & 0.173 \\
\hline$\geq 35.0$ & $2.44(1.15,5.14)$ & 0.019 & $3.05(1.26,7.37)$ & 0.013 \\
\hline \multicolumn{5}{|l|}{ Fundal height } \\
\hline$<36.0^{\circ}$ & Reference & & Reference & \\
\hline$\geq 36.0$ & $2.97(1.99,4.43)$ & $<0.001$ & $1.69(0.99,2.87)$ & 0.052 \\
\hline
\end{tabular}

Abbreviations: ANC, antenatal care; CI, confidence interval; EBL, estimated blood loss; OR, odds ratio; PPH, postpartum hemorrhage. 
Table 4. Multivariable analysis of association between intrapartum characteristics and postpartum hemorrhage $(\mathrm{n}=795)$.

\begin{tabular}{|c|c|c|c|c|}
\hline & \multicolumn{4}{|c|}{ Multivariable Analysis } \\
\hline & \multicolumn{2}{|c|}{$\mathrm{EBL} \geq 500 \mathrm{~mL}$} & \multicolumn{2}{|c|}{ EBL $>1000 \mathrm{~mL}$} \\
\hline & Adjusted OR (95\%CI) & $p$-Value & $\begin{array}{l}\text { Adjusted OR } \\
(95 \% \mathrm{CI})\end{array}$ & $p$-Value \\
\hline Labor augmentation & & & & \\
\hline No & Reference & & Reference & \\
\hline Yes & $2.34(1.55,3.53)$ & $<0.001$ & $3.50(2.06,5.96)$ & $<0.001$ \\
\hline Require manual removal of placenta & & & & \\
\hline Absence & Reference & & Reference & \\
\hline Presence & $49.35(11.66,208.89)$ & $<0.001$ & $26.59(12.30,57.50)$ & $<0.001$ \\
\hline Delivery & & & & \\
\hline Spontaneous delivery & Reference & & Reference & \\
\hline $\begin{array}{l}\text { Instrumental delivery } \\
\text { Episiotomy wound }\end{array}$ & $2.58(1.48,4.51)$ & 0.001 & $1.26(0.57,2.76)$ & 0.560 \\
\hline No tear & Reference & & Reference & \\
\hline First or second degree tear & $1.16(0.78,1.72)$ & 0.465 & $1.26(0.70,2.28)$ & 0.434 \\
\hline $\begin{array}{c}\text { Third or fourth degree tear } \\
\text { Fetal weight }\end{array}$ & $25.89(3.28,204.29)$ & 0.002 & $1.24(0.26,5.95)$ & 0.789 \\
\hline$<3500$ & Reference & & Reference & \\
\hline $3500-4000$ & $2.11(1.41,3.16)$ & $<0.001$ & $1.65(0.92,2.98)$ & 0.095 \\
\hline$>4000$ & $5.92(1.72,20.37)$ & 0.005 & $5.42(1.48,19.85)$ & 0.011 \\
\hline
\end{tabular}

\section{Discussion}

In this retrospective case-control study of women undergoing vaginal delivery at a Thai-Myanmar border hospital in Northern Thailand, the overall incidence of PPH and severe $\mathrm{PPH}$ was $5.55 \%$ and $1.84 \%$, respectively. The robust risk factors for $\mathrm{PPH}$ and severe $\mathrm{PPH}$ were elderly pregnancy, minority groups, nulliparous, history of previous $\mathrm{PPH}$, BMI $\geq 35 \mathrm{~kg} / \mathrm{m}^{2}$, requirement of manual removal of placenta, labor augmentation, and fetal weight $>4000 \mathrm{gm}$.

In this study, the PPH incidence was higher than that of the South-east Asian countries at $4.88 \%$ [4] and much higher than other reports from Thailand, ranging from 1.98 to $2.40 \%[11,22]$. This was in concordance with a previous report that identified a higher PPH rate in district hospitals compared to urban or tertiary care centers [5]. The higher incidence of PPH in our study could be explained by the type of clinical settings, which took place in rural areas where standard equipment and supplies are often lacked [32]. Previous studies have found that hospital levels significantly affect resource allocation and the PPH management quality $[8,33]$.

Several antepartum risk factors in pregnant women delivered vaginally were identified in our study, which were elderly pregnancy [8,34], nulliparous [35,36], history of previous $\mathrm{PPH}[5,9,12], \mathrm{BMI} \geq 35 \mathrm{~kg} / \mathrm{m}^{2}$ [35,37], and minority group. All these factors were supported by previous studies and were independent risk factors for both $\mathrm{PPH}$ and severe $\mathrm{PPH}$ according to our analysis. Although some factors were significant in only one of the PPH definitions, including Burmese nationality, inadequate ANC, history of instrumental delivery, and fundal height $\geq 36 \mathrm{~cm}$, they should not be overlooked during an initial risk assessment of the pregnant women.

Our study population comes from a rural area on the Thai-Myanmar border with large numbers of migrants and minorities, mostly hill-tribes, which were a significant risk factor for both PPH and severe PPH in our study. This association could be multifactorial as the minorities have a specific context of socioeconomic aspect including poor economic condition, healthcare coverage and accessibility, lack of formal education, and language barrier [38]. Previous studies showed that pregnant women who live in a disadvantaged area or have low-income were at higher risk of PPH [16] and other poor maternal health outcomes [39]. Lower family income was also reported to be significantly related to unhealthy behaviors, increased maternal infection, and unintended pregnancy, leading to a lower antenatal care commitment [40]. 
Racial and ethnic disparities have a significant effect on both maternal morbidity, mortality, and postpartum hemorrhage [12,15,41,42]. South-East Asian ethnicity was also reported as a risk factor for PPH [43]. After adjusting for known risk factors that may bias the estimate of the effect of race, especially maternal age and BMI [44], we found that Burmese nationality was not a significant risk factor for PPH but severe PPH, which indicates that Burmese women are hemorrhaging less frequently than local Thai women, but hemorrhage appears to be more serious when they do. Biological differences may influence the effect of race or ethnicity disparities on PPH. A previous study attempting to identify genetic background that influences the PPH reported that the gene polymorphism carries a protective effect against PPH [45]. Because PPH incidence depends on various factors; genetic predisposition such as a defect in coagulation or tissue elasticity might also lead to higher PPH incidence in different races or ethnicities [46]. However, current evidence regarding genetic and racial entities as possible independent risk factors for PPH is still limited. Besides, healthcare provider bias and implicit bias may affect different levels of care to women of different racial/ethnic groups and affect doctor-patient interaction [47]. Furthermore, antenatal care visits of fewer than five times, and previous instrumental delivery history were identified as PPH risk factors. Inadequate ANC results in a lack of crucial maternal education that involves self-management and self-monitoring skills that are important for pregnant women to detect early warning signs and the physicians to identify other relevant risk factors and medical conditions that might affect the postpartum outcomes $[48,49]$. One study found that history of previous instrumental delivery was associated with uterine atony and increasing instrumental delivery in the following pregnancy [50].

During the intrapartum period, three factors were risk factors for PPH and severe PPH: requiring manual removal of placenta, Labor augmentation, and fetal weight more than $4000 \mathrm{gm}$, or fetal macrosomia. Not surprisingly, the strongest risk factor in our study is requiring manual removal of placenta due to retained placental tissue, which is universally known as the second-leading cause of PPH [34,51]. Augmentation of labor was also supported by many previous observational studies [52,53], as well as being consistent with one randomized control trial, which found that labor augmentation increases the volume of postpartum blood loss [54]. The hypothesized mechanism was the reduction in the uterine contractility after birth due to desensitized oxytocin receptors at the uterus [55]. Fetal macrosomia may increase postpartum blood loss via multiple pathways. The most direct mechanism is the distension of uterus due to large fetal size, which causes uterine atony after birth [56]. Studies also showed that fetal macrosomia increased the risk of instrumental delivery and third-degree tear of an episiotomy wound $[8,57,58]$. Other factors were significant predictors for only PPH: instrumental delivery, third- or fourth-degree tear of an episiotomy wound, fetal weight between 3500 and $4000 \mathrm{gm}$, and fundal height more than $36 \mathrm{~cm}$.

The main strengths of the study are the specific domains of the patients. We collect data from Thai-Myanmar border hospitals in the Maesai district. A unique health care setting where racial and ethnicity disparities and low socioeconomic status were present and evidence was still lacking, allowing us to evaluate local or context-specific risk factors of PPH. To identify independent risk factors for $\mathrm{PPH}$, we employed two definitions of $\mathrm{PPH}$, both at 500 and $1000 \mathrm{~mL}$. Only factors with a significant association with both PPH definitions were concluded as robust risk factors for PPH.

This study had some limitations. First, the design was case-control, and the data were retrospectively collected, which might be subjected to several types of bias (i.e., selection bias). However, as controls came from the same source population as cases and were randomly sampled from the same year, the selection bias and bias due to time effect were therefore minimized. Moreover, all the data were collected from routine, standardized records that possess all the data on essential variables. Thus, the quality of the data was adequate. In our study, observer bias was properly handled by the fact that the history of exposure to any risk factor or the occurrence of any risk that predisposes the patients to 
postpartum hemorrhage during the intrapartum period were recorded in a standardized routine record form by the attending midwives prior to the time of endpoint verification. Thus, the recorders of all the data on the study determinants were, at that time, blinded to the outcomes. Using of standardized risk evaluation form to gather information upon admission also eliminates the presence of recall bias, as the final status of the patient was unknown at the time of data collection. Second, the sample size may not provide adequate statistical power to identify the statistical significance of some predictors on severe $\mathrm{PPH}$. However, these factors showed the same direction of the effect for PPH and were consistent with previous studies. Third, different methods to estimate postpartum blood loss were used. Visual estimation was used before 2016, whereas a standard collecting bag was used after 2016. This difference might result in differential verification bias of clinical endpoints. Regarding this issue, conditional logistic regression was used to provide the combined estimates after the stratification of patients according to their study periods. In addition, sensitivity analysis with multi-level logistic models showed consistent results to conditional logistic models. Finally, our study was conducted in a specific healthcare setting, limiting the generalizability of the results to the general population.

\section{Conclusions}

Several clinical factors were identified as independent risk factors for PPH and severe PPH in a Thai-Myanmar border community hospital, which were elderly pregnancy, nulliparous, previous PPH history, BMI $\geq 35 \mathrm{~kg} / \mathrm{m}^{2}$, requiring manual removal of placenta, labor augmentation, and fetal weight $>4000 \mathrm{gm}$. Although most clinical factors identified in our study were already supported by previous evidence, our study provides additional data on the effect of race and ethnicity on the occurrence of PPH in the Asian population. Apart from other known factors, particular attention should be given to pregnant women who were minority groups as PPH risk significantly increased in this population.

Supplementary Materials: The following are available online at https:/ / www.mdpi.com/article/ 10.3390/ijerph18094633/s1, Table S1: Incidence of postpartum hemorrhage of the patient cohort in each year, Table S2: Comparison of antepartum characteristics between severe PPH cases and non-severe PPH controls $(n=795)$, Table S3: Comparison of antepartum characteristics between severe PPH cases and non-severe PPH controls $(n=795)$, Table S4: Multivariable multi-level analysis of association between antepartum characteristics and severe postpartum hemorrhage $(n=795)$, Table S5: Multivariable multi-level analysis of association between intrapartum characteristics and severe postpartum hemorrhage $(n=795)$.

Author Contributions: Conceptualization, W.T., N.E., K.T. and P.P.; methodology, K.T. and P.P.; software, P.P.; validation, K.T. and P.P.; formal analysis, K.T. and P.P.; investigation, W.T. and N.E.; resources, P.P.; data curation, W.T. and N.E.; writing-original draft preparation, W.T. and N.E.; writing-review and editing, K.T. and P.P.; visualization, P.P.; supervision, P.P.; project administration, P.P. All authors have read and agreed to the published version of the manuscript.

Funding: This research received no external funding.

Institutional Review Board Statement: The study was conducted according to the guidelines of the Declaration of Helsinki and approved by the Office for Research Ethics Committee of Chiang Rai Provincial Public Health Office, Ministry of Public Health [CRPPHO No 27/2562 Study code 6/2562].

Informed Consent Statement: Patient consent was waived due to a retrospective manner of the analysis and the use of de-identified data.

Data Availability Statement: The datasets used and/or analyzed during the current study are available from the corresponding author on reasonable request.

Acknowledgments: We would like to thank all team members of the Labor Unit, Maesai Hospital, for their cooperation during the data collection and to Jayanton Patumanond for providing us with useful insight for the design and the statistical analysis of the study. This study was partially supported by the Faculty of Medicine, Chiang Mai University.

Conflicts of Interest: The authors declare no conflict of interest. 


\section{References}

1. Say, L.; Chou, D.; Gemmill, A.; Tunçalp, Ö.; Moller, A.-B.; Daniels, J.; Gülmezoglu, A.M.; Temmerman, M.; Alkema, L. Global Causes of Maternal Death: A WHO Systematic Analysis. Lancet Glob. Health 2014, 2, e323-e333. [CrossRef]

2. Committee on Practice Bulletins-Obstetrics. Practice Bulletin No. 183: Postpartum Hemorrhage. Obstet. Gynecol. 2017, 130, e168-e186. [CrossRef]

3. Dahlke, J.D.; Mendez-Figueroa, H.; Maggio, L.; Hauspurg, A.K.; Sperling, J.D.; Chauhan, S.P.; Rouse, D.J. Prevention and Management of Postpartum Hemorrhage: A Comparison of 4 National Guidelines. Am. J. Obstet. Gynecol. 2015, 213, 76.e1-76.e10. [CrossRef]

4. Carroli, G.; Cuesta, C.; Abalos, E.; Gulmezoglu, A.M. Epidemiology of Postpartum Haemorrhage: A Systematic Review. Best Pract. Res. Clin. Obstet. Gynaecol. 2008, 22, 999-1012. [CrossRef] [PubMed]

5. Prapawichar, P.; Ratinthorn, A.; Utriyaprasit, K.; Viwatwongkasem, C. Maternal and Health Service Predictors of Postpartum Hemorrhage across 14 District, General and Regional Hospitals in Thailand. BMC Pregnancy Childbirth 2020, 20, 172. [CrossRef] [PubMed]

6. Talungchit, P.; Liabsuetrakul, T. Clinical Audit of Postpartum Hemorrhage at District-Level and Referral-Level Hospitals in Southern Thailand. J. Med. Assoc. Thai. 2012, 95, 1244.

7. Abedzadeh-Kalahroudi, M. Prevention of Postpartum Hemorrhage: Our Options. Nurs. Midwifery Stud. 2015,4 , e29641. [CrossRef]

8. Tort, J.; Rozenberg, P.; Traoré, M.; Fournier, P.; Dumont, A. Factors Associated with Postpartum Hemorrhage Maternal Death in Referral Hospitals in Senegal and Mali: A Cross-Sectional Epidemiological Survey. BMC Pregnancy Childbirth 2015, 15, 235. [CrossRef] [PubMed]

9. Nyfløt, L.T.; Sandven, I.; Stray-Pedersen, B.; Pettersen, S.; Al-Zirqi, I.; Rosenberg, M.; Jacobsen, A.F.; Vangen, S. Risk Factors for Severe Postpartum Hemorrhage: A Case-Control Study. BMC Pregnancy Childbirth 2017, 17, 17. [CrossRef] [PubMed]

10. Said, A.S.; Manji, K.P. Risk Factors and Outcomes of Fetal Macrosomia in a Tertiary Centre in Tanzania: A Case-Control Study. BMC Pregnancy Childbirth 2016, 16, 243. [CrossRef]

11. Lertbunnaphong, T.; Leetheeragul, J.; Thitadilok, W. Risk Factors of Primary Postpartum Hemorrhage in Siriraj Hospital. Siriraj Med. J. 2010, 62, 195-198.

12. Magann, E.F.; Evans, S.; Hutchinson, M.; Collins, R.; Lanneau, G.; Morrison, J.C. Postpartum Hemorrhage after Cesarean Delivery: An Analysis of Risk Factors. South. Med. J. 2005, 98, 681-685. [CrossRef]

13. Shields, L.E.; Wiesner, S.; Fulton, J.; Pelletreau, B. Comprehensive Maternal Hemorrhage Protocols Reduce the Use of Blood Products and Improve Patient Safety. Am. J. Obstet. Gynecol. 2015, 212, 272-280. [CrossRef]

14. Tunçalp, O.; Souza, J.P.; Gülmezoglu, M. New WHO Recommendations on Prevention and Treatment of Postpartum Hemorrhage. Int. J. Gynaecol. Obstet. 2013, 123, 254-256. [CrossRef] [PubMed]

15. Bryant, A.; Mhyre, J.M.; Leffert, L.R.; Hoban, R.A.; Yakoob, M.Y.; Bateman, B.T. The Association of Maternal Race and Ethnicity and the Risk of Postpartum Hemorrhage. Anesth. Analg. 2012, 115, 1127-1136. [CrossRef]

16. Choe, S.-A.; Min, H.-S.; Cho, S.-I. The Income-Based Disparities in Preeclampsia and Postpartum Hemorrhage: A Study of the Korean National Health Insurance Cohort Data from 2002 to 2013. SpringerPlus 2016, 5, 895. [CrossRef]

17. Liabsuetrakul, T.; Palanukunwong, K.; Chinduereh, A.; Oumudee, N. Evaluation of a Multifaceted Postpartum HemorrhageManagement Intervention in Community Hospitals in Southern Thailand. Int. J. Gynaecol. Obstet. 2017, 139, 39-44. [CrossRef]

18. Pothisiri, W. Postpartum Care in Thailand: Experience, Practice and Policy. Ph.D. Thesis, London School of Economics and Political Science, London, UK, 2010.

19. Ende, H.B.; Lozada, M.J.; Chestnut, D.H.; Osmundson, S.S.; Walden, R.L.; Shotwell, M.S.; Bauchat, J.R. Risk Factors for Atonic Postpartum Hemorrhage: A Systematic Review and Meta-Analysis. Obstet. Gynecol. 2021, 137, 305-323. [CrossRef] [PubMed]

20. Lao, T.T.; Sahota, D.S.; Cheng, Y.K.Y.; Law, L.W.; Leung, T.Y. Advanced Maternal Age and Postpartum Hemorrhage-Risk Factor or Red Herring? J. Matern.-Fetal Neonatal Med. 2014, 27, 243-246. [CrossRef]

21. Sittiparn, W.; Siwadune, T. Risk Score for Prediction of Postpartum Hemorrhages in Normal Labor at Chonburi Hospital. J. Med. Assoc. Thai. 2017, 100, 382. [PubMed]

22. Rueangchainikhom, W.; Srisuwan, S.; Prommas, S.; Sarapak, S. Risk Factors for Primary Postpartum Hemorrhage in Bhumibol Adulyadej Hospital. J. Med. Assoc. Thai. 2009, 92, 1586.

23. Tuporn, N.; Ratanasiri, A.; Nutravong, T.; Boonprasert, K.; Pikul, T.N. Risk Scoring System for the Prediction of Postpartum Blood Loss over 300 ML at Chiang Rai Regional Hospital. Siriraj Med. J. 2019, 71, 10-116. [CrossRef]

24. Phinyo, P.; Patumanond, J. Indicators for Extended Length of Stay in the Emergency Service Unit of a Thai Community Hospital: A Multi-Level Analysis. Epidemiol. Biostat. Public Health 2020, 17, 1-12. [CrossRef]

25. Van Stralen, K.J.; Dekker, F.W.; Zoccali, C.; Jager, K.J. Case-Control Studies-An Efficient Observational Study Design. Nephron Clin. Pract. 2010, 114, c1-c4. [CrossRef]

26. Vandenbroucke, J.P.; Pearce, N. Case-Control Studies: Basic Concepts. Int. J. Epidemiol. 2012, 41, 1480-1489. [CrossRef] [PubMed]

27. Mgaya, A.H.; Massawe, S.N.; Kidanto, H.L.; Mgaya, H.N. Grand Multiparity: Is It Still a Risk in Pregnancy? BMC Pregnancy Childbirth 2013, 13, 241. [CrossRef]

28. World Health Organization. Iron Deficiency Anemia. Assessment, Prevention, and Control. A Guide for Programme Managers; WHO: Geneva, Switzerland, 2001; pp. 47-62. 
29. Cheng, Y.W.; Caughey, A.B. Defining and Managing Normal and Abnormal Second Stage of Labor. Obstet. Gynecol. Clin. N. Am. 2017, 44, 547-566. [CrossRef]

30. Herman, A. Complicated Third Stage of Labor: Time to Switch on the Scanner. Ultrasound Obstet. Gynecol. 2000, 15, 89-95. [CrossRef]

31. Heinze, G.; Puhr, R. Bias-Reduced and Separation-Proof Conditional Logistic Regression with Small or Sparse Data Sets. Stat. Med. 2010, 29, 770-777. [CrossRef] [PubMed]

32. Li, X.; Zhu, J.; Dai, L.; Li, M.; Miao, L.; Liang, J.; Wang, Y. Trends in Maternal Mortality Due to Obstetric Hemorrhage in Urban and Rural China, 1996-2005. J. Perinat. Med. 2011, 39, 35-41. [CrossRef]

33. Kruk, M.E.; Leslie, H.H.; Verguet, S.; Mbaruku, G.M.; Adanu, R.M.K.; Langer, A. Quality of Basic Maternal Care Functions in Health Facilities of Five African Countries: An Analysis of National Health System Surveys. Lancet Glob. Health 2016, 4, e845-e855. [CrossRef]

34. Bateman, B.T.; Berman, M.F.; Riley, L.E.; Leffert, L.R. The Epidemiology of Postpartum Hemorrhage in a Large, Nationwide Sample of Deliveries. Anesth. Analg. 2010, 110, 1368-1373. [CrossRef]

35. Durmaz, A.; Komurcu, N. Relationship Between Maternal Characteristics and Postpartum Hemorrhage: A Meta-Analysis Study. J. Nurs. Res. JNR 2018, 26, 362-372. [CrossRef]

36. Combs, C.A.; Murphy, E.L.; Laros, R.K. Factors Associated with Postpartum Hemorrhage with Vaginal Birth. Obstet. Gynecol. 1991, 77, 69-76. [PubMed]

37. Mavrides, E.; Allard, S.; Chandraharan, E.; Collins, P.; Green, L.; Hunt, B.J.; Riris, S.; Thomson, A.J. on behalf of the Royal College of Obstetricians and Gynaecologists. Prevention and Management of Postpartum Haemorrhage. BJOG Int. J. Obstet. Gynaecol. 2017, 124, e106-e149. [CrossRef]

38. Kunstadter, P. Ethnicity, Socioeconomic Characteristics and Knowledge, Beliefs and Attitudes about HIV among Yunnanese Chinese, Hmong, Lahu and Northern Thai in a North-Western Thailand Border District. Cult. Health Sex. 2013, 15, S383-S400. [CrossRef]

39. Lindquist, A.; Noor, N.; Sullivan, E.; Knight, M. The Impact of Socioeconomic Position on Severe Maternal Morbidity Outcomes among Women in Australia: A National Case-Control Study. BJOG Int. J. Obstet. Gynaecol. 2015, 122, 1601-1609. [CrossRef] [PubMed]

40. Räisänen, S.; Kramer, M.R.; Gissler, M.; Saari, J.; Heinonen, S. Unemployment at Municipality Level Is Associated with an Increased Risk of Small for Gestational Age Births-A Multilevel Analysis of All Singleton Births during 2005-2010 in Finland. Int. J. Equity Health 2014, 13, 95. [CrossRef]

41. Harvey, S.A.; Lim, E.; Gandhi, K.R.; Miyamura, J.; Nakagawa, K. Racial-Ethnic Disparities in Postpartum Hemorrhage in Native Hawaiians, Pacific Islanders, and Asians. Hawaii J Med. Public Health 2017, 76, 128-132. [PubMed]

42. Wetta, L.A.; Szychowski, J.M.; Seals, S.; Mancuso, M.S.; Biggio, J.R.; Tita, A.T. Risk Factors for Uterine Atony/Postpartum Hemorrhage Requiring Treatment after Vaginal Delivery. Am. J. Obstet. Gynecol. 2013, 209, 51.e1-51.e6. [CrossRef]

43. Al-Zirqi, I.; Vangen, S.; Forsen, L.; Stray-Pedersen, B. Prevalence and Risk Factors of Severe Obstetric Haemorrhage. BJOG Int. J. Obstet. Gynaecol. 2008, 115, 1265-1272. [CrossRef]

44. Gregory, K.D.; Korst, L.M. Age and Racial/Ethnic Differences in Maternal, Fetal, and Placental Conditions in Laboring Patients. Am. J. Obstet. Gynecol. 2003, 188, 1602-1606, discussion 1606-1608. [CrossRef] [PubMed]

45. Biguzzi, E.; Franchi, F.; Acaia, B.; Ossola, W.; Nava, U.; Paraboschi, E.M.; Asselta, R.; Peyvandi, F. Genetic Background and Risk of Postpartum Haemorrhage: Results from an Italian Cohort of 3219 Women. Haemoph. Off. J. World Fed. Hemoph. 2014, 20, e377-e383. [CrossRef] [PubMed]

46. Salomon, O.; Steinberg, D.M.; Pshithizki, M.; Zalel, Y.; Lerner, A.; Rosenberg, N.; Achiron, R. The Influence of Prothrombotic Polymorphisms and Obstetrical and Medical Variables on the Length of Secondary Postpartum Hemorrhage. J. Womens Health 2005, 14, 306-310. [CrossRef]

47. FitzGerald, C.; Hurst, S. Implicit Bias in Healthcare Professionals: A Systematic Review. BMC Med. Ethics 2017, 18, 19. [CrossRef]

48. Geller, S.E.; Adams, M.G.; Kelly, P.J.; Kodkany, B.S.; Derman, R.J. Postpartum Hemorrhage in Resource-Poor Settings. Int. J. Gynaecol. Obstet. 2006, 92, 202-211. [CrossRef] [PubMed]

49. Mairiga, A. How Birth Interval and Antenatal Care Affects Postpartum Haemorrhage Prevention in Maiduguri, Nigeria. J. Appl. Pharm. Sci. 2013, 3, 36-39. [CrossRef]

50. Lurie, S.; Steinberg, N.; Tannus, S.; Golan, A.; Sadan, O. Mode of Delivery in a Subsequent Pregnancy Following Previous Instrumental Delivery. J. Perinat. Med. 2013, 41, 283-286. [CrossRef] [PubMed]

51. Lutomski, J.E.; Byrne, B.M.; Devane, D.; Greene, R.A. Increasing Trends in Atonic Postpartum Haemorrhage in Ireland: An 11-Year Population-Based Cohort Study. BJOG Int. J. Obstet. Gynaecol. 2012, 119, 306-314. [CrossRef]

52. Al-Zirqi, I.; Vangen, S.; Forsén, L.; Stray-Pedersen, B. Effects of Onset of Labor and Mode of Delivery on Severe Postpartum Hemorrhage. Am. J. Obstet. Gynecol. 2009, 201, 273.e1-273.e9. [CrossRef]

53. Rossen, J.; Okland, I.; Nilsen, O.B.; Eggebø, T.M. Is There an Increase of Postpartum Hemorrhage, and Is Severe Hemorrhage Associated with More Frequent Use of Obstetric Interventions? Acta Obstet. Gynecol. Scand. 2010, 89, 1248-1255. [CrossRef] [PubMed]

54. Mansy, A. Does Labor Augmentation with Oxytocin Increase the Risk of Postpartum Hemorrhage? A Randomized Controlled Trial. Clin. Mother Child. Health 2017, 14. [CrossRef] 
55. Phaneuf, S.; Rodríguez Liñares, B.; TambyRaja, R.L.; MacKenzie, I.Z.; López Bernal, A. Loss of Myometrial Oxytocin Receptors during Oxytocin-Induced and Oxytocin-Augmented Labour. J. Reprod. Fertil. 2000, 120, 91-97. [CrossRef] [PubMed]

56. Jolly, M.C.; Sebire, N.J.; Harris, J.P.; Regan, L.; Robinson, S. Risk Factors for Macrosomia and Its Clinical Consequences: A Study of 350,311 Pregnancies. Eur. J. Obstet. Gynecol. Reprod. Biol. 2003, 111, 9-14. [CrossRef]

57. Fong, A.; Wu, E.; Pan, D.; Chung, J.H.; Ogunyemi, D.A. Temporal Trends and Morbidities of Vacuum, Forceps, and Combined Use of Both. J. Matern.-Fetal Neonatal Med. 2014, 27, 1886-1891. [CrossRef]

58. De Leeuw, J.W.; Struijk, P.C.; Vierhout, M.E.; Wallenburg, H.C. Risk Factors for Third Degree Perineal Ruptures during Delivery. BJOG Int. J. Obstet. Gynaecol. 2001, 108, 383-387. [CrossRef] 